\title{
High selectivity epoxidation of ethylene in chemical looping setup
}

\author{
E. J. Marek ${ }^{1,2 *}$, S. Gabra ${ }^{2}$, J. S. Dennis ${ }^{2}$, S. A. Scott ${ }^{1}$ \\ ${ }^{1}$ Department of Engineering, University of Cambridge, Trumpington Street, CB2 1PZ, United Kingdom \\ ${ }^{2}$ Department of Chemical Engineering and Biotechnology, University of Cambridge, Philippa Fawcett Drive, \\ CB3 0AS, United Kingdom \\ *Corresponding author ejm94@cam.ac.uk
}

\begin{abstract}
We describe the remarkable performance of a new catalyst for the chemical looping (CL-) epoxidation of ethylene, performed at atmospheric pressure and without any promoters added to either the catalyst or the feed gas. To undertake the CL-epoxidation of ethylene, silver was used as the catalyst, supported on either the perovskite $\mathrm{SrFeO}_{3}$ or $\mathrm{Ce}$-modified $\mathrm{SrFeO}_{3}$. Here, the oxygen for the reaction is supplied to the silver catalyst from the active solid support, not from the gas stream. When the support has been reduced and depleted of oxygen, it is regenerated in a separate step with air, which makes the process cyclic and closes a chemical loop. Thus, there is no need to co-feed gaseous oxygen along with the ethylene feed, an important improvement in safety. Two methods were used to synthesise Ce-modified materials, employing either (i) the mechanical mixing of powdered $\mathrm{CeO}_{2}$ and the solid precursors of the perovskite, or (ii) the impregnation of a solution of cerium nitrate into solid particles of $\mathrm{SrFeO}_{3}$. In both cases, the materials were calcined to produce a mixture of $\mathrm{CeO}_{2}$ and $\mathrm{SrFeO}_{3}$. Both $\mathrm{CeO}_{2}-\mathrm{SrFeO}_{3}$ materials surpassed the unmodified $\mathrm{SrFeO}_{3}$ for CL-epoxidation. For the $\mathrm{CeO}_{2}-\mathrm{SrFeO}_{3}$ prepared by mechanical mixing, the production of ethylene oxide was stable over 15 cycles, giving $60 \%$ selectivity at $10 \%$ conversion of $\mathrm{C}_{2} \mathrm{H}_{4}$. In contrast, the material prepared by impregnation gave up to $85 \%$ selectivity but only in the first cycle of reduction, with the performance degrading over subsequent cycles. The reported results are better than the 50\% selectivity achieved for the classical epoxidation using pure silver as the catalyst and feeds of gaseous ethylene and oxygen, without reaction promoters.
\end{abstract}

Keywords: epoxidation, chemical looping, silver, perovskite, $\mathrm{CeO}_{2}$

\section{Introduction}

Ethylene oxide (EO), is an important chemical commodity, with an annual production (2016) of about 26 Mte [1]. Industrially, ethylene oxide is produced by the epoxidation of ethylene, where gaseous streams of ethylene and pure $\mathrm{O}_{2}$ are passed through a bed of catalyst, usually silver supported on alumina. Pure silver as a catalyst gives about 50\% selectivity for the epoxide [2]. In the industrial process, the selectivity is improved by adding 1) reaction promoters to the catalyst, and 2) inhibitors of 
complete combustion to the gaseous feed, achieving typically, 70-90\% selectivity and $10 \%$ conversion of ethylene $[3,4]$.

The classical direct epoxidation with gaseous $\mathrm{O}_{2}$ is highly efficient, as it has been continually developed and optimised since 1937 [4]. Despite being a mature technology, the direct oxidation of ethylene to EO is still considered challenging because of safety considerations. By creating a mixture of oxygen, ethylene and ethylene oxide, the process must manage the inherent and significant risk of explosion. Moreover, to reach $90 \%$ selectivity, it employs pure $\mathrm{O}_{2}$, produced from expensive cryogenic air separation. To reach the highly optimised performance, the process requires long-lasting conditioning of the catalyst and needs to run continuously within a range of narrowly-specified operating conditions [5].

Recently, a new process has been proposed, where epoxidation is carried out via a so-called chemical looping (CL-) route [6]. Here, the oxygen for the reaction is supplied to the silver catalyst from the active solid support, not from the gas stream. When the support is reduced and depleted of oxygen, it is regenerated in a separate step with air, which makes the process cyclic and closes a chemical loop. The benefits of CL-epoxidation come from not using gaseous oxygen in reduction; this allows (1) aiming for higher conversions in a single pass, (2) avoiding the cost of purified oxygen, (3) avoiding the risk of creation of explosive mixtures.

Here, to improve the selectivity of $20 \%$ achieved by Chan et al. [6] to a practical value, we have modified the support material with $\mathrm{CeO}_{2}$. Materials were prepared either by mechanical mixing of $\mathrm{CeO}_{2}$ with the precursors of $\mathrm{SrFeO}_{3}$ and then calcined together; or by depositing $\mathrm{CeO}_{2}$ on the $\mathrm{SrFeO}_{3}$ particles by incipient impregnation. Then, silver, $15 \mathrm{wt} \%$, was introduced on both types of materials via impregnation. After the final calcination, materials were investigated for chemical looping epoxidation. For comparison, epoxidation on $\mathrm{CeO}_{2}$ impregnated with $15 \mathrm{wt} \% \mathrm{Ag}$ was also investigated.

\section{Experimental}

\subsection{Material preparation}

\section{$\mathrm{SrFeO}_{3}$ particles}

$\mathrm{SrFeO}_{3}$ was prepared using solid-state synthesis by the mechanical mixing of solid precursors, followed by calcination. This method results in primarily perovskite phase [7]. Stoichiometric amounts of $\mathrm{SrCO}_{3}$ (0.72 mol, >98\%, Sigma Aldrich) and $\mathrm{Fe}_{2} \mathrm{O}_{3}(0.36 \mathrm{~mol}, \geq 95 \%$, Fisher Scientific) were mixed in a planetary ball mill (MTI, MSK-SFM-1) for 3h at $25 \mathrm{~Hz}$. Ethanol (50 mL, 99.8\%, Fisher Scientific) was added to help with the mixing. The resulting dense paste was dried for 24 hours at $50^{\circ} \mathrm{C}$ and sieved afterwards to $180-355 \mu \mathrm{m}$. Particles in this sieve size range were calcined in a muffle furnace four times. In each calcination, materials were held at $1000^{\circ} \mathrm{C}$ for $3 \mathrm{~h}$, with ramping at $5^{\circ} \mathrm{C} \mathrm{min}^{-1}$. The resulting stoichiometry of the perovskite was evaluated as $\mathrm{SrFeO}_{2.82}$ as described in [7]. For simplicity, the perovskite is nonetheless denoted here as $\mathrm{SrFeO}_{3}$. 


\section{$\mathrm{CeO}_{2}$ particles}

$\mathrm{CeO}_{2}$ particles were prepared by the decomposition of the nitrate salt, $\mathrm{Ce}\left(\mathrm{NO}_{3}\right)_{3} \cdot 6 \mathrm{H}_{2} \mathrm{O}(>99 \%$, Sigma Aldrich). The nitrate was slowly heated in a muffle furnace $\left(1^{\circ} \mathrm{C} \mathrm{min}^{-1}\right)$ to $500^{\circ} \mathrm{C}$ and kept at this temperature for $4 \mathrm{~h}$. Afterwards, particles were sieved to two fractions, $<180 \mu \mathrm{m}$ and 180-355 $\mu \mathrm{m}$. The resulting particles were very brittle and could be crushed readily during handling.

\section{$\mathrm{SrFeO}_{3}$ with addition of $5 \mathrm{~mol}_{\%} \mathrm{CeO}_{2}$}

This material was made either by solid state synthesis or by a wet-impregnation method. Material prepared by solid-state synthesis is denoted here as $\left(\mathrm{CeO}_{2}\right) \mathrm{ss}\left(\mathrm{SrFeO}_{3}\right)$. Here, powders of $\mathrm{SrCO}_{3}(0.5$ mol $)$ and $\mathrm{Fe}_{2} \mathrm{O}_{3}(0.25 \mathrm{~mol})$ were mixed with $\mathrm{CeO}_{2}(0.025 \mathrm{~mol},<180 \mu \mathrm{m})$ using a ball mill. The above followed the same procedure of mixing, drying, sieving and calcination as $\mathrm{SrFeO}_{3}$. Material prepared by incipient impregnation is denoted as $\left(\mathrm{CeO}_{2}\right) \mathrm{impr}\left(\mathrm{SrFeO}_{3}\right)$. Cerium nitrate, $0.0025 \mathrm{~mol}$ was dissolved in $1.5 \mathrm{~mL}$ deionized water and added dropwise to $0.0475 \mathrm{~mol} \mathrm{SrFeO}_{3}, 180-355 \mu \mathrm{m}$, whilst agitating with a spatula. The sample was dried at $120^{\circ} \mathrm{C}$ for $12 \mathrm{~h}$ in static air and then calcined at $600^{\circ} \mathrm{C}$ for $4 \mathrm{~h}$. For both $\left(\mathrm{CeO}_{2}\right) \mathrm{impr}\left(\mathrm{SrFeO}_{3}\right)$ and $\left(\mathrm{CeO}_{2}\right) \mathrm{ss}\left(\mathrm{SrFeO}_{3}\right)$, the samples were synthesised in 3 batches on different days, $\sim 5 \mathrm{~g}$ each.

\section{Impregnation with Ag}

The solid supports, described above, were impregnated with $\mathrm{AgNO}_{3}(\geq 99.8 \%$, Fisher Scientific), using $1.3895 \mathrm{~g} \mathrm{AgNO}_{3}$ dissolved in $1.2 \mathrm{~mL}$ water per $5.0000 \mathrm{~g}$ of the supporting material. The solution was added dropwise with manual agitation by a spatula. The sample was dried at $120^{\circ} \mathrm{C}$ for $12 \mathrm{~h}$ in static air and then calcined at $550^{\circ} \mathrm{C}$ for $5 \mathrm{~h}$. The procedure resulted in $15 \mathrm{wt} \% \mathrm{Ag}$ loading.

As a reference sample, $\alpha-\mathrm{Al}_{2} \mathrm{O}_{3}$ particles (Alfa Aesar, 180-300 $\mu \mathrm{m}$ ) were impregnated with $15 \mathrm{wt} \% \mathrm{Ag}$ using the same methodology as for the other samples.

\subsection{Material characterisation}

Phase identification was performed on X-ray powder diffraction (XRD) patterns. Scans were collected with a PANalytical Empyrean diffractometer, using $\mathrm{Cu}-\mathrm{K} \alpha$ radiation with a voltage of $40 \mathrm{kV}$ and current $40 \mathrm{~mA}$. A typical diffractogram was collected in a $2 \theta$ range of 10 to $150^{\circ}$, with a step size of $0.0167^{\circ}$ and $60 \mathrm{sec}$ of scanning duration per step. Rietveld or Pawley refinement was applied using Topas Academic V5 software [8]. The reference structures used for phase analysis were: SrO (ICSD 105548), $\mathrm{Sr}_{3} \mathrm{Fe}_{2} \mathrm{O}_{7}$ (ICSD 74422), $\mathrm{SrFe}_{12} \mathrm{O}_{19}$ (ICSD 69022), $\mathrm{SrFeO}_{3}$ (ICSD 91062), $\mathrm{CeO}_{2}$ (ICSD 72155), Ag (ICSD 52545), $\mathrm{SrCeO}_{3}$ (ICSD 71352) and $\mathrm{Sr}_{2} \mathrm{CeO}_{4}$ (ICSD 86768).

Thermogravimetric experiments were undertaken in a TGA/DSC1 Mettler Toledo thermogravimetric analyser with a horizontal reaction chamber. Oxygen release from materials was analysed in $\mathrm{N}_{2}$ or $\mathrm{H}_{2} / \mathrm{N}_{2}$ during a heating step to $900^{\circ} \mathrm{C}$ (TPR); reoxidation was observed when the material was cooled in air to $50^{\circ} \mathrm{C}$ (TPO). The sample $(\sim 10-20 \mathrm{mg},<180 \mu \mathrm{m})$ was placed in an alumina crucible and heated to $900^{\circ} \mathrm{C}$ 
(in air, $\mathrm{H}_{2} / \mathrm{N}_{2}$ or $\mathrm{N}_{2}$ ) then cooled to $50^{\circ} \mathrm{C}$ (in air), both with $10^{\circ} \mathrm{C} \min ^{-1}$. The chamber was continuously

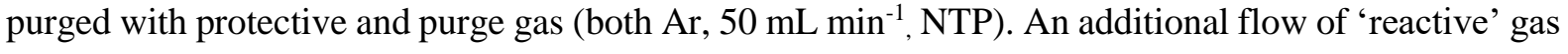
(50 mL min ${ }^{-1}$, NTP) was introduced above the crucible. Gas flows containing, variously, $5 \mathrm{vol} \% \mathrm{H}_{2} / \mathrm{N}_{2}$, air or $\mathrm{N}_{2}$ were used as 'reactive' streams in TPR-TPO. All gases were BOC, >99.998\%.

Low-temperature redox experiments in the TGA were performed isothermally, at $270^{\circ} \mathrm{C}$. The 1 -cycle experiment consisted of one epoxidation cycle, comprising reduction using $5.16 \mathrm{vol} \% \mathrm{C}_{2} \mathrm{H}_{4} / \mathrm{N}_{2}$ for 30 min, followed by 1 min purge in $\mathrm{N}_{2}$ and 80 min oxidation in air. The 5-cycle experiment consisted of five epoxidation cycle, with reduction in $5.16 \mathrm{vol} \% \mathrm{C}_{2} \mathrm{H}_{4} / \mathrm{N}_{2}$ for $5 \mathrm{~min}$, followed by 1 min purge in $\mathrm{N}_{2}$ and 20 min oxidation in air. Due to the dilution from the protective and purge gases continuously flowing through the TGA chamber, the actual concentration of the introduced gases was always $\sim 1 / 3$ of the nominal concentration in the cylinder.

Scanning electron microscopy (SEM) images were taken using a Leo GEMINI 1530 VP. Samples were mounted on copper tape. Images were obtained at an accelerating voltage of $2.4 \mathrm{kV}$ and a working distance of $\sim 5.5 \mathrm{~mm}$. EDS acquisition and analysis was performed using Oxford Instruments Aztec Energy X-maxN system.

\subsection{Experiments on the chemical looping epoxidation of ethylene}

Experiments were undertaken in a packed bed held in a vertically-positioned quartz tube $8 \mathrm{~mm}$ i.d., 200 mm length. To support the bed of material, the tube was equipped with a sintered disc, positioned 75 $\mathrm{mm}$ from the bottom. Materials were loaded from the top, creating three layers of bed: 1) $2 \mathrm{~g}$ of $\alpha-\mathrm{Al}_{2} \mathrm{O}_{3}$ (Boud Minerals, 355-425 $\mu \mathrm{m}$ ); 2) $2 \mathrm{~g}$ active material with Ag catalyst, 180-355 $\mu \mathrm{m}$; 3 ) $2 \mathrm{~g}$ of $\alpha-\mathrm{Al}_{2} \mathrm{O}_{3}$. The alumina was used to preheat and distribute the gas flow uniformly. A thermocouple (K type) was inserted from the top of the reactor with the tip positioned in the middle of the active layer. The thermocouple was used to control the heating of a heating tape, wrapped around the reactor. The gases used in the experiments were $5.16 \mathrm{vol} \% \mathrm{C}_{2} \mathrm{H}_{4}$ in $\mathrm{N}_{2}$ (for the epoxidation step), $\mathrm{N}_{2}$ (for purge), and air (for reoxidation).The flow rate of the gases (each $200 \mathrm{~mL} \mathrm{~min}^{-1}$, NTP) was controlled with rotameters and checked with a gas flowmeter every day before experiments. The residence time for gases in the bed of catalyst was $0.29 \mathrm{~s}$, while GHSV based on the volume of catalyst was $6250 \mathrm{~h}^{-1}$. A cycling experiment was performed by switching gases with solenoid valves according to a time-based programme. The epoxidation step (reduction) lasted for $90 \mathrm{~s}$, while the regeneration (reoxidation) lasted $900 \mathrm{~s}$, the two stages separated by a purge with $\mathrm{N}_{2}$ for $120 \mathrm{~s}$. The feed of gas entered at the top of the reactor, while the exit gas was directed to an FTIR analyser for continuous measurement of gas composition (Multigas 2030, MKS Instruments, equipped with $5.11 \mathrm{~m}$ gas cell and a $\mathrm{HgCdTe}$ detector, cooled with liquid $\mathrm{N}_{2}$ ). A single measurement was performed every $1.87 \mathrm{~s}$, averaging 8 scans of the band $800-4600 \mathrm{~cm}^{-1}$, at a resolution of $0.5 \mathrm{~cm}^{-1}$. The spectra were analysed for $\mathrm{C}_{2} \mathrm{H}_{4}, \mathrm{CO}_{2}, \mathrm{CO}, \mathrm{H}_{2} \mathrm{O}$ and EO using MKS's MG2000 software. The $\mathrm{CO}$ was detected only in small amounts < $40 \mathrm{ppm} ; \mathrm{H}_{2} \mathrm{O}$ was not quantified but rather evaluated from the stoichiometry of two combustion reactions: $0.5 \mathrm{C}_{2} \mathrm{H}_{4}+$ 
$3 / 2 \mathrm{O}_{2} \rightarrow \mathrm{CO}_{2}+\mathrm{H}_{2} \mathrm{O}$, and $0.5 \mathrm{C}_{2} \mathrm{H}_{4}+\mathrm{O}_{2} \rightarrow \mathrm{CO}+\mathrm{H}_{2} \mathrm{O}$, i.e., 1 mol of $\mathrm{CO}_{2}$ or $\mathrm{CO}$ generated implied that $1 \mathrm{~mol}$ of $\mathrm{H}_{2} \mathrm{O}$ was also generated, and that 1.5 or $1 \mathrm{~mol}$ of $\mathrm{O}_{2}$ was consumed. No acetaldehyde was detected.

The cycling experiments were performed for all prepared materials, investigating their reactivity towards epoxidation or full combustion. The same experiment was performed on bare alumina as a control, where only ethylene but no reaction products were detected (with results shown in the supporting information, SFig. 8). This control experiment validated the experimental and measurement setup.

Comparison of chemical looping and direct epoxidation of ethylene

For the comparison, chemical looping was also performed using the same methodology as above but with lower $p \mathrm{C}_{2} \mathrm{H}_{4}$. One cycle comprised: i) 2 min purge with $\mathrm{N}_{2}$, ii) 1.5 min reduction in 2.58 vol\% $\mathrm{C}_{2} \mathrm{H}_{4}$ (in $\mathrm{N}_{2}$ ), iii) 2 min purge with $\mathrm{N}_{2}$, iv) 15 min reoxidation in 10.5 vol\% $\mathrm{O}_{2}\left(\right.$ in $\mathrm{N}_{2}$ ). Direct epoxidation carried out for by continuously co-feeding $2.58 \mathrm{vol} \% \mathrm{C}_{2} \mathrm{H}_{4}$ and $5 \mathrm{vol} \% \mathrm{O}_{2}$ (in $\mathrm{N}_{2}$ ) for up to 1 hour. Finally, direct epoxidation was also tried in a cycling mode, following the cycles in chemical looping but performing step ii) in a mixture of $2.58 \mathrm{vol} \% \mathrm{C}_{2} \mathrm{H}_{4}, 5 \mathrm{vol} \% \mathrm{O}_{2}\left(\right.$ in $\left._{2}\right)$. In these experiments, the gas flowrates were kept at $200 \mathrm{~mL} \mathrm{~min}^{-1}$, NTP.

\section{Results}

\subsection{Materials characterisation}

The final composition and the crystal structure of prepared materials were examined with XRD. The results of phase identification for $\mathrm{CeO}_{2}, \mathrm{SrFeO}_{3},\left(\mathrm{CeO}_{2}\right) \mathrm{impr}\left(\mathrm{SrFeO}_{3}\right),\left(\mathrm{CeO}_{2}\right) \mathrm{ss}\left(\mathrm{SrFeO}_{3}\right)$, without $\mathrm{Ag}$ loading are shown in Fig. 1. The results from the Rietveld refinement are provided in SFig. 1 in the supporting information. Cerium can substitute $\mathrm{Sr}$ in $\mathrm{SrFeO}_{3}$ by up to $20 \mathrm{~mol} \%$ [9] and a small shift in peak position was noticed for samples with added $\mathrm{CeO}_{2}$. Partial substitution of $\mathrm{Sr}$ should also result in the presence of Sr-rich phases. Such a phase was found only in the sample with $\mathrm{CeO}_{2}$ prepared by ball milling, containing small amounts of $\mathrm{Sr}_{3} \mathrm{Fe}_{2} \mathrm{O}_{7}$. The content of the impurity decreased after impregnation with $\mathrm{Ag}$, possibly as a result of the treatment with the nitrate solution during the impregnation. Perovskites are sensitive to acidic solutions, and $\mathrm{Sr}_{3} \mathrm{Fe}_{2} \mathrm{O}_{7}$ can be removed by washing with citric acid [10]. If during impregnation, the Ag precipitated quickly on the particle surface, then the $\mathrm{pH}$ of the water remaining in pores might have fallen, exposing the material to acidic conditions. 


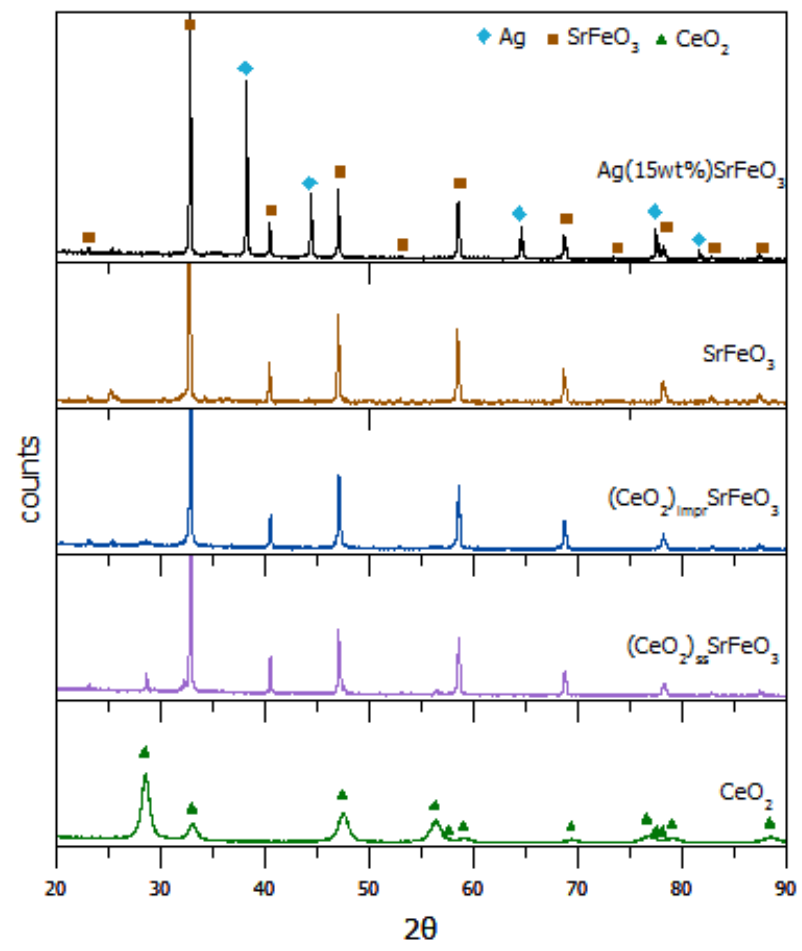

Fig. 1. XRD results of all supporting materials and $\mathrm{SrFeO}_{3}$ impregnated with $15 \mathrm{wt} \% \mathrm{Ag}$. Refinement and the full scans are provided in the supporting information.

For samples with $\mathrm{CeO}_{2}$ added to $\mathrm{SrFeO}_{3}$, the XRD scans confirmed that $\mathrm{CeO}_{2}$ was present as a separate phase. In the case of the $\mathrm{CeO}_{2}$-impregnated sample, the broadening of the $\mathrm{CeO}_{2}$ peaks indicates nanoparticles $(\sim 5 \mathrm{~nm})$, while for the ball-milled material the size of $\mathrm{CeO}_{2}$ grains was $\sim 300 \mathrm{~nm}$. Similar conclusions come from the SEM-EDS images in Fig. 2 and SFig. 2 in the supporting information. In the ball-milled material, separated large $\mathrm{CeO}_{2}$ particles can be seen. For comparison, impregnation of $\mathrm{CeO}_{2}$ on the $\mathrm{SrFeO}_{3}$ resulted in a uniform distribution of $\mathrm{CeO}_{2}$ on the surface, as would be expected for a distribution of nanoparticles.

Interestingly, the dispersion of silver differed in the two types of Ce-containing samples, suggesting that $\mathrm{Ag}$ may affiliate differently with both supports. For the $\mathrm{Ag}-\left(\mathrm{CeO}_{2}\right) \mathrm{ss}\left(\mathrm{SrFeO}_{3}\right)$, silver was present as small particles (161 nm, XRD), comparable to silver particles on the unmodified $\mathrm{SrFeO}_{3}(205 \mathrm{~nm})$. In contrast, for the double-impregnated sample, $\mathrm{Ag}-\left(\mathrm{CeO}_{2}\right) \mathrm{impr}\left(\mathrm{SrFeO}_{3}\right)$ the average size of the $\mathrm{Ag}$ particle was bigger $(312 \mathrm{~nm})$. Previous studies have already shown that silver may wet surfaces differently, depending on the support characteristics. In the extreme case, such as for the $\mathrm{Al}_{2} \mathrm{O}_{3}$ used by Chan et al. [6] or the $\mathrm{CeO}_{2}$ used in the present work (illustrated in SFig. 3 in the supporting information), micron size clusters of $\mathrm{Ag}$ were found. The distribution of silver is of importance in epoxidation because the size of Ag particles influences the selectivity of the reaction. In the classical epoxidation with $\mathrm{O}_{2(\mathrm{~g})}$, nano-sized particles of Ag promote the secondary oxidation of ethylene oxide [11]. 
The presence of $\mathrm{CeO}_{2}$ in the form of nanoparticles in the $\left.\mathrm{Ag}-\left(\mathrm{CeO}_{2}\right) \mathrm{impr}_{(\mathrm{SrFeO}}\right)$ can also be seen in SEM micrographs given in SFig. 4 in the supporting information. Otherwise, the supporting perovskite structure is visually similar for all catalysts.

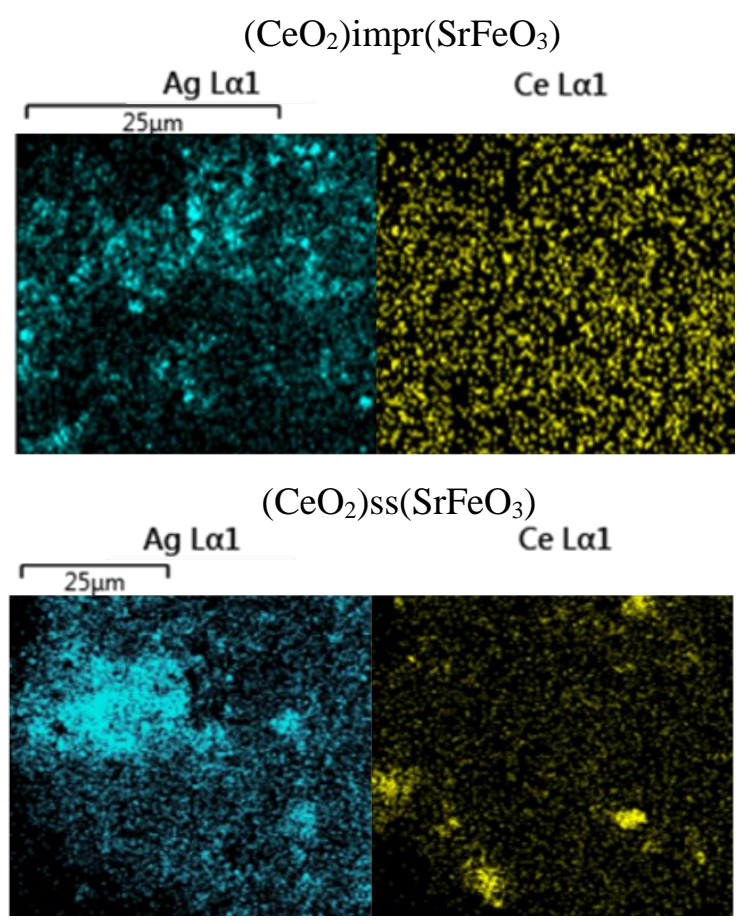

Fig. 2. Distribution of silver and cerium in $\left(\mathrm{CeO}_{2}\right)$ impr $\left(\mathrm{SrFeO}_{3}\right)$ and $\left(\mathrm{CeO}_{2}\right) \mathrm{ss}\left(\mathrm{SrFeO}_{3}\right)$. Images acquired with SEM-EDS. Distribution of $\mathrm{Sr}, \mathrm{Fe}$ and $\mathrm{O}$ was uniform across the samples.

Surfaces of $\mathrm{CeO}_{2}, \mathrm{Ag}$ and $\mathrm{SrFeO}_{3}$ can easily be covered with impurities, usually carbonates or hydroxides [12-14] when left exposed to air. The impurities are not visible in XRD but can be detected by surface-analysing techniques, such as XPS or Raman spectroscopy [15]. The impurities on either of the components decompose during thermal treatment in air (given in SFig. 5 in the supporting information).

Here, samples were cleaned directly before all TPR experiments, to ensure that any change in mass was associated with reduction of the materials. In the cleaning cycle in air up to $900^{\circ} \mathrm{C}$, the finite rate of

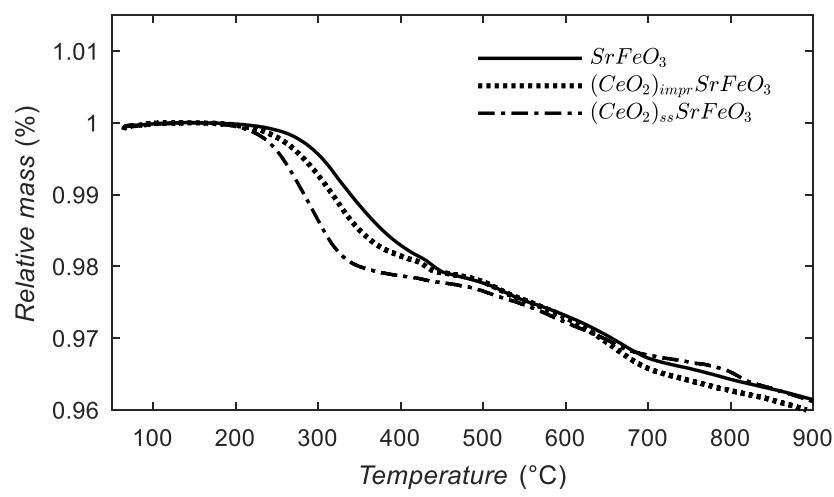

Fig. 3. Mass of samples impregnated with 15 wt\% of Ag during the TPR in $\mathrm{H}_{2} / \mathrm{N}_{2}$, measured in TGA. 
sublimation of $\mathrm{Ag}$ cannot be ignored and will add to the observed mass loss. The partial pressure of silver rises from $3 \mathrm{~Pa}$ at $600^{\circ} \mathrm{C}$ to $230 \mathrm{~Pa}$ at $900{ }^{\circ} \mathrm{C}$ [16]. The sublimation also gives a limit to the calcination temperatures in Ag-catalyst preparation. The rate of sublimation of $\mathrm{Ag}$ depends on the particle size [17], and should be similar in all catalysts because the size of Ag particles was of the same order of magnitude. Therefore, the mass loss possibly induced by sublimation was assumed the same in all samples.

Results from the TPR in $\mathrm{H}_{2} / \mathrm{N}_{2}$ of three samples: $15 \mathrm{wt} \% \mathrm{Ag}$ on: $\mathrm{SrFeO}_{3},\left(\mathrm{CeO}_{2}\right)_{\mathrm{ss}} \mathrm{SrFeO}_{3}$ and

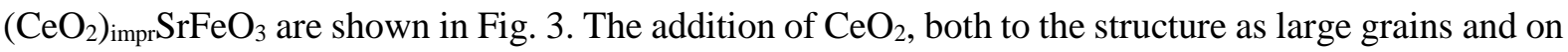
the surface increased the rate of reduction and lowered the starting temperature. The total oxygen released during TPR was similar for all three materials, probably because the amount of $\mathrm{CeO}_{2}$ was small (5 mol\%).

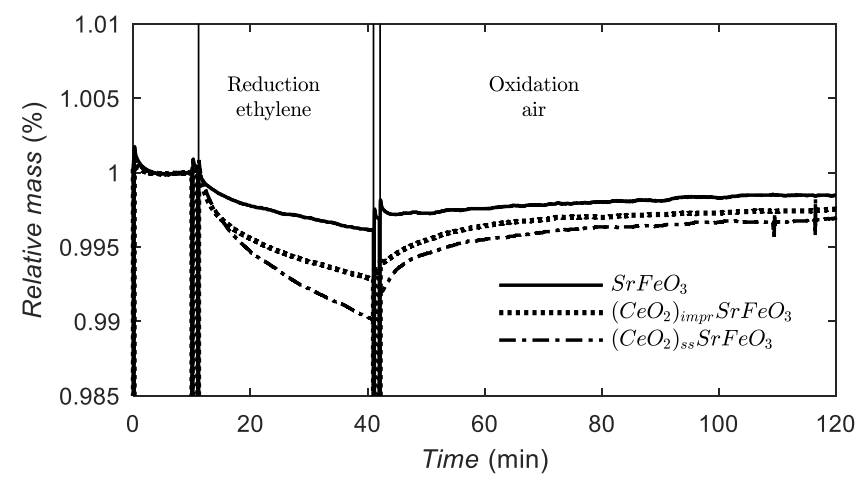

Fig. 4. Mass change of samples impregnated with 15 wt $\%$ of $\mathrm{Ag}$ during a reduction in $\mathrm{C}_{2} \mathrm{H}_{4}$ (30 min) and reoxidation in air $(80 \mathrm{~min})$, measured in $T G A$. Isothermal experiment at $270{ }^{\circ} \mathrm{C}$.

The mass changes during reduction in $\mathrm{C}_{2} \mathrm{H}_{4}$ and reoxidation in air during an isothermal experiment at $270^{\circ} \mathrm{C}$ in the TGA are shown in Fig. 4. It can be seen that both $\mathrm{CeO}_{2}$-containing materials reduced faster than the catalyst supported on pure $\mathrm{SrFeO}_{3}$. Initially, the rate of mass loss was similar for $\left(\mathrm{CeO}_{2}\right)_{\mathrm{ss}} \mathrm{SrFeO}_{3}$ and $\left(\mathrm{CeO}_{2}\right)_{\mathrm{impr}} \mathrm{SrFeO}_{3}$. Both materials quickly reoxidised when exposed to air. Neither $\mathrm{SrFeO}_{3}$ nor $\mathrm{CeO}_{2}$-enriched $\mathrm{SrFeO}_{3}$ returned to the starting mass; however, the relative mass gain for $\mathrm{CeO}_{2}$-containing materials was higher than for $\mathrm{SrFeO}_{3}$. The same behaviour of incomplete oxidation was observed when the experiment was continued for a few redox cycles. The oxygen loss and uptake during 5 cycles in TGA is shown in the supporting information in SFig. 6, which shows that despite the incomplete regeneration, the release of oxygen in reduction was stable between cycles, indicating that slow oxidation did not influence the overall activity of the materials. 


\subsection{Chemical looping epoxidation}

Results from epoxidation in the packed bed are presented in Fig. 5. During the reduction stage, both ethylene oxide and $\mathrm{CO}_{2}$ were produced in the experiments with $15 \mathrm{wt} \% \mathrm{Ag}$ impregnated on $\mathrm{SrFeO}_{3}$, $\left(\mathrm{CeO}_{2}\right)$ impr $\left(\mathrm{SrFeO}_{3}\right)$ and $\left(\mathrm{CeO}_{2}\right) \operatorname{ss}\left(\mathrm{SrFeO}_{3}\right)$. Notable differences are visible amongst the three catalysts. For the pure $\mathrm{SrFeO}_{3}$, the total activity quickly degraded from cycle to cycle, as judged by the decreasing amount of ethylene oxide produced. This result is in agreement with the observations of Chan et al. [6]. For the $\mathrm{SrFeO}_{3}$ impregnated with $\mathrm{CeO}_{2}$, the amount of $\mathrm{EO}$ in the first cycle was higher than $\mathrm{CO}_{2}$. The distribution of the gas products is reversed in the subsequent cycles, but the mean level of EO production stayed above that for $\mathrm{SrFeO}_{3}$. Finally, the sample with $\mathrm{CeO}_{2}$ ball-milled during synthesis gave the highest levels of EO, which were maintained in successive cycles.

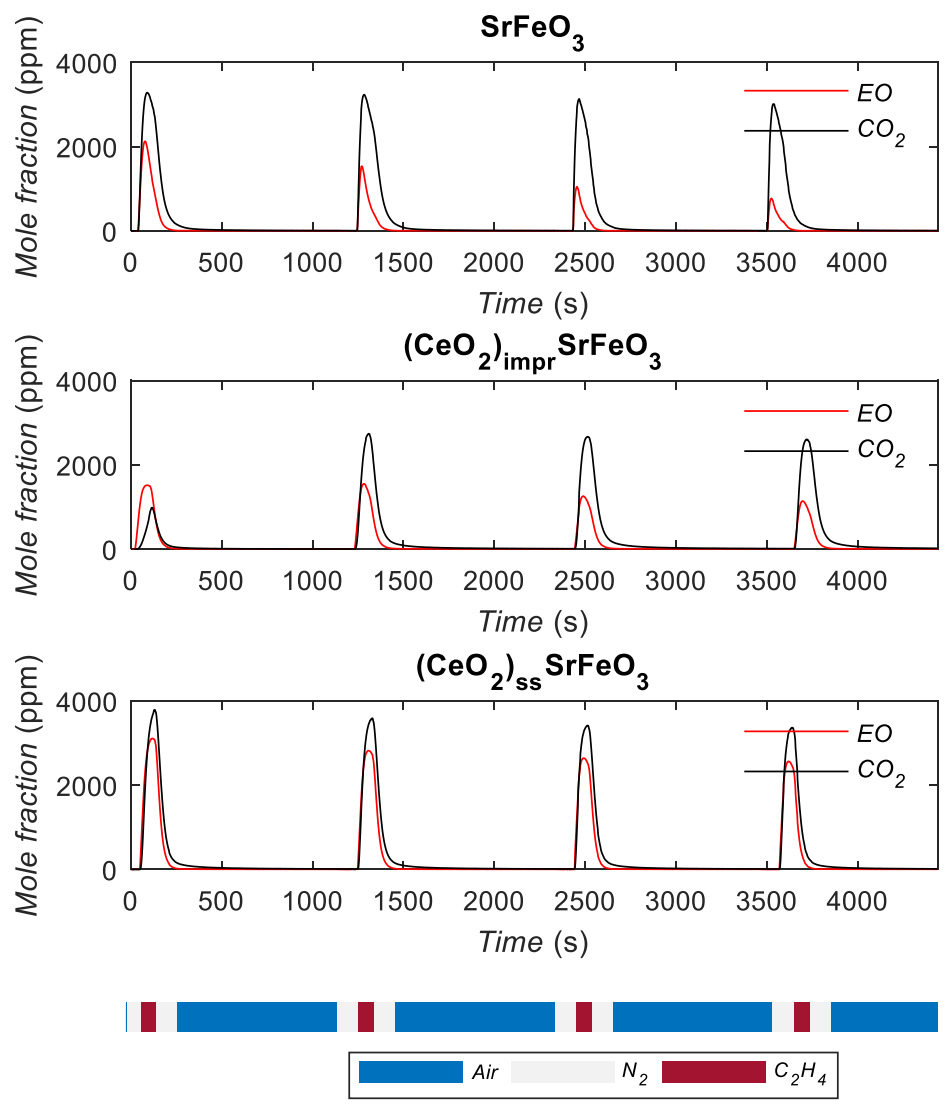

Fig. 5. $\mathrm{EO}$ and $\mathrm{CO}_{2}$ profiles collected in the first four cycles of epoxidation experiments in a packed bed. One cycle consisted of: i) 2 min purge with $\mathrm{N}_{2}$, ii) 1.5 min reduction in 5.16 vol\% $\mathrm{C}_{2} \mathrm{H}_{4}$ (in $\mathrm{N}_{2}$ ), iii) 2 min purge of $\mathrm{N}_{2}$, iv) 15 min reoxidation in air. Each catalyst contained $15 \mathrm{wt} \% \mathrm{Ag}$.

For the sample consisting of $15 \mathrm{wt} \% \mathrm{Ag}$ on pure $\mathrm{CeO}_{2}$, the epoxide was produced only in the first cycle. Later, only complete combustion was observed (shown in SFig. 9 in the supporting information), giving a conversion of $\mathrm{C}_{2} \mathrm{H}_{4} \sim 2 \%$, as seen in Fig. 6. Ethylene also readily coked on $\mathrm{CeO}_{2}$, with the carbon deposit combusted when the material was exposed to air in the reoxidation stage. No coking was observed for any other catalyst. 
Oxygen carriers (catalyst support)
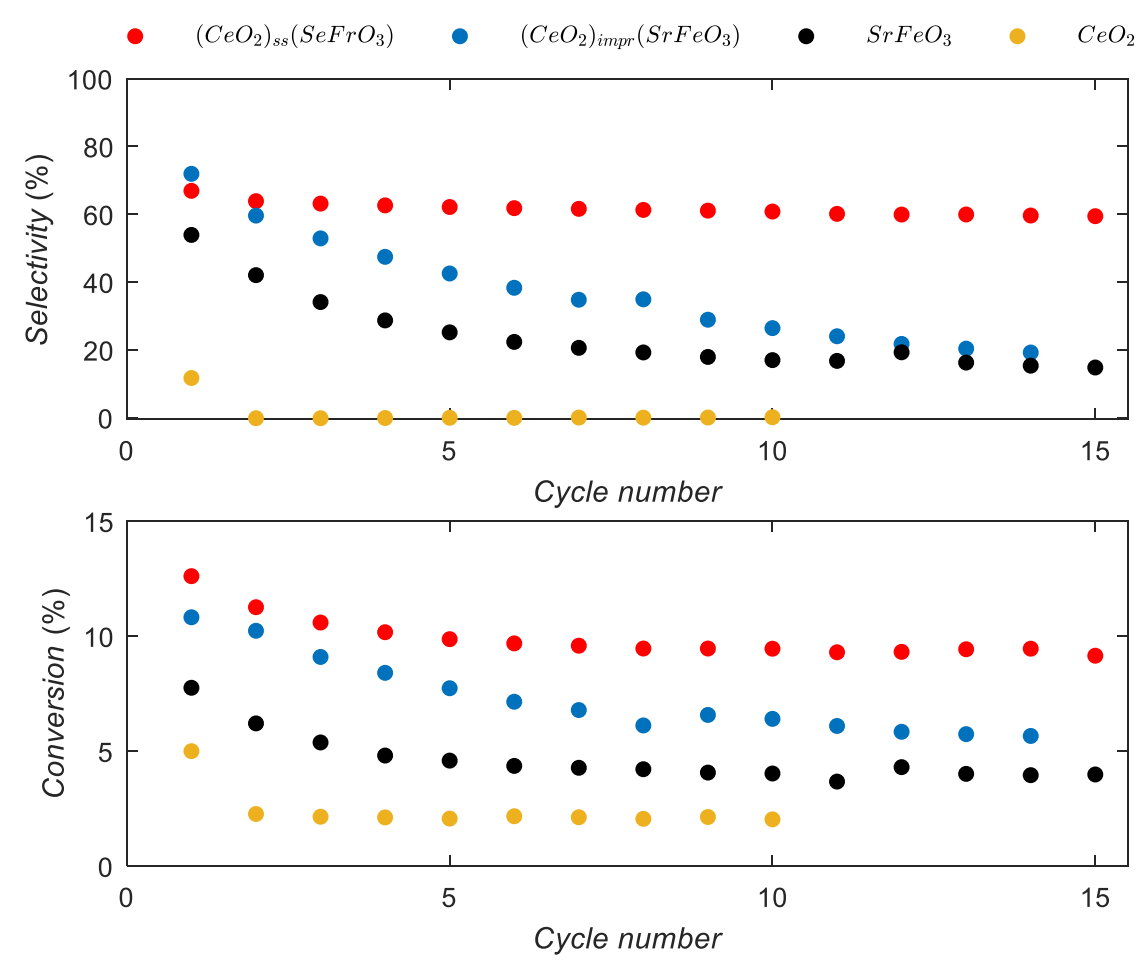

Fig. 7. Selectivity and conversion for $\mathrm{SrFeO}_{3},\left(\mathrm{CeO}_{2}\right) s s\left(\mathrm{SrFeO}_{3}\right),\left(\mathrm{CeO}_{2}\right)$ impr $\left(\mathrm{SrFeO}_{3}\right)$, and $\mathrm{CeO}_{2}$ during chemical looping epoxidation in a packed bed. Each catalyst contained $15 \mathrm{wt} \%$ Ag. Single experiment for up to 15 cycles.

Selectivities towards EO and overall conversions of $\mathrm{C}_{2} \mathrm{H}_{4}$ obtained in the packed bed throughout the long experiments (10 - 15 cycles) are presented in Fig. 6. Both parameters are the highest and the most stable for $\left(\mathrm{CeO}_{2}\right) \mathrm{ss}\left(\mathrm{SrFeO}_{3}\right)$, levelling at $\sim 60 \%$ selectivity at $10 \%$ conversion $\left(\mathrm{GHSV}\right.$ of $\left.6250 \mathrm{~h}^{-1}\right)$. For $\left(\mathrm{CeO}_{2}\right)$ impr $\left(\mathrm{SrFeO}_{3}\right)$, the first cycle gave the highest selectivity for EO, 72\%. However, the performance of the material quickly decayed with number of cycles, similar to unmodified $\mathrm{SrFeO}_{3}$.
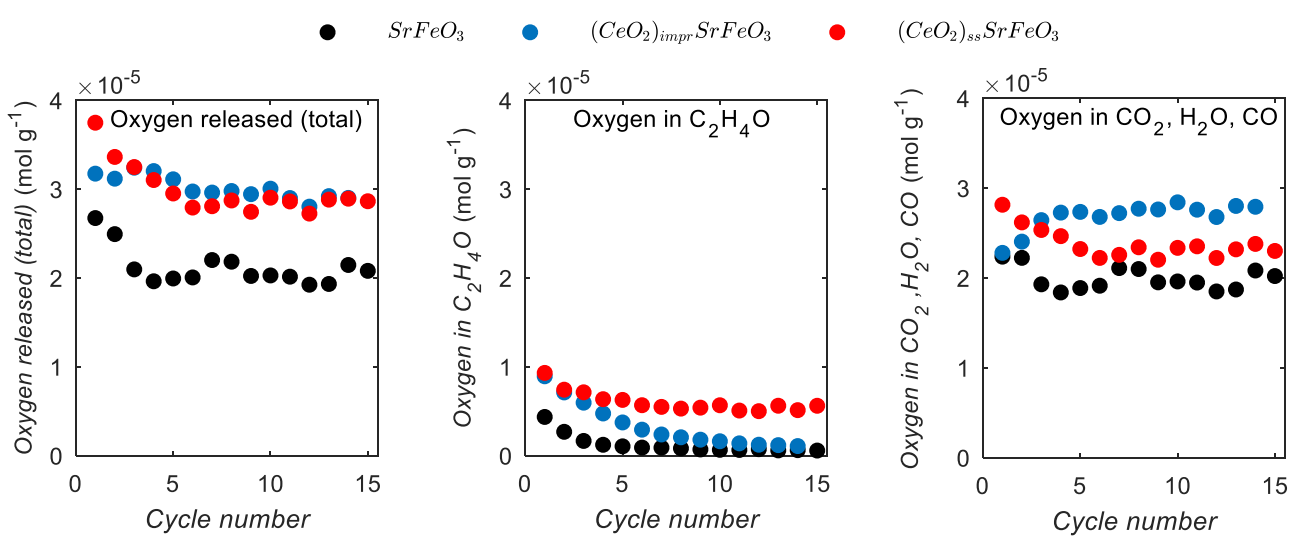

Fig. 6. Oxygen release during chemical looping epoxidation in a packed bed. Reduction with $\mathrm{C}_{2} \mathrm{H}_{4}$ lasted for $1.5 \mathrm{~min}$. Each catalyst contained $15 \mathrm{wt} \% \mathrm{Ag}$. 
Fig. 7 shows that the total amount of oxygen released by all catalysts levelled after the few first cycles and remained stable throughout the rest of the experiments. The amount of oxygen appearing in undesirable products $\left(\mathrm{CO}_{2}, \mathrm{H}_{2} \mathrm{O}\right.$, and $\left.\mathrm{CO}\right)$ during epoxidation increased with the number of cycles for $\left(\mathrm{CeO}_{2}\right) \mathrm{impr}\left(\mathrm{SrFeO}_{3}\right)$ and decreased for $\left(\mathrm{CeO}_{2}\right) \mathrm{ss}\left(\mathrm{SrFeO}_{3}\right)$. At the same time, the production of $\mathrm{EO}$ changed significantly for all materials except for $\left(\mathrm{CeO}_{2}\right) \mathrm{ss}\left(\mathrm{SrFeO}_{3}\right)$, and this factor was responsible for the change in the selectivity and conversion of $\mathrm{C}_{2} \mathrm{H}_{4}$ seen in Fig. 6.

In order to analyse the repeatability of the experimental results for $\left.\mathrm{Ag}-\left(\mathrm{CeO}_{2}\right) \mathrm{impr}(\mathrm{SrFeO})_{3}\right)$ and $\mathrm{Ag}-$ $\left(\mathrm{CeO}_{2}\right) \mathrm{ss}\left(\mathrm{SrFeO}_{3}\right)$, materials were prepared in 3 batches on different days, $\sim 5 \mathrm{~g}$ each, using the same supporting materials to be impregnated. Repeatability was compared between samples within the same batch and samples from different batches. One batch allowed for two epoxidation experiments and repeatability for a batch of $\mathrm{Ag}-\left(\mathrm{CeO}_{2}\right) \mathrm{impr}\left(\mathrm{SrFeO}_{3}\right)$ was within $10 \%$ error, both for selectivity and conversion. The repeatability between $\mathrm{CeO}_{2}$-containing batches differed between materials as shown in Fig. 8. For the $\mathrm{CeO}_{2}$-impregnated $\mathrm{SrFeO}_{3}$, the first cycle gave the broadest spread of results, with selectivity as high as $85.2 \%$ at $3.9 \%$ conversion or as low as $59.9 \%$ at $14.0 \%$ conversion. The variation between the batches decreased with cycling. Preparation of $\mathrm{Ag}-\left(\mathrm{CeO}_{2}\right) \mathrm{impr}\left(\mathrm{SrFeO}_{3}\right)$ required double impregnation (firstly $\mathrm{CeO}_{2}$, then $\mathrm{Ag}$ ), which might have introduced more variability to the resulting materials, depending on a distribution of $\mathrm{CeO}_{2}$ on the perovskite support and the distribution of $\mathrm{Ag}$,
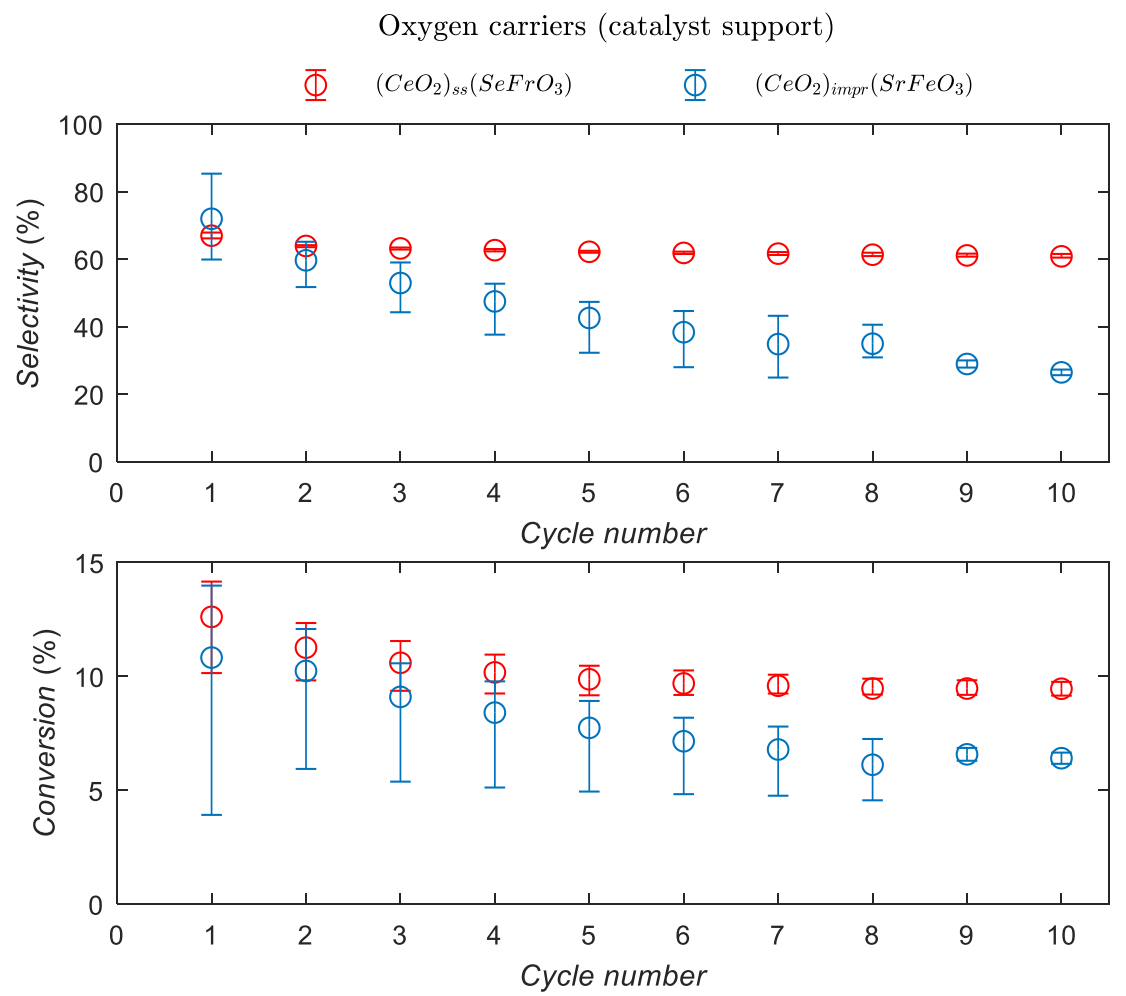

Fig. 8. Selectivity towards $\mathrm{EO}$ and $\mathrm{C}_{2} \mathrm{H}_{4}$-conversion in chemical looping experiments in a packed bed with $\left(\mathrm{CeO}_{2}\right) \mathrm{ss}\left(\mathrm{SrFeO} \mathrm{O}_{3}\right)$ and $\left(\mathrm{CeO}_{2}\right) \mathrm{impr}\left(\mathrm{SrFeO}_{3}\right)$. Each catalyst contained $15 \mathrm{wt} \% \mathrm{Ag}$. Graphs present results from three experiments for each material, each carried out with samples from separate batches, prepared on different days. For both supports, one of the batches was run for eight cycles only. 
both on $\mathrm{CeO}_{2}$ and the perovskite. In contrast, all 3 batches of $\mathrm{Ag}-\left(\mathrm{CeO}_{2}\right) \operatorname{ss}\left(\mathrm{SrFeO}_{3}\right)$ performed in a repeatable and stable way, giving $\sim 61 \%$ selectivity in the $8^{\text {th }}$ cycle at $9.5 \%$ conversion.

The results from the experiments aiming for comparison of chemical looping and direct epoxidation are presented in Table 1 . As expected, when the catalyst with $\alpha-\mathrm{Al}_{2} \mathrm{O}_{3}$ was used in the chemical looping mode, almost no reaction was observed. For the direct epoxidation, with $\mathrm{O}_{2(\mathrm{~g})}$ and $\mathrm{C}_{2} \mathrm{H}_{4}$ co-fed, $\mathrm{Ag}-\mathrm{Al}_{2} \mathrm{O}_{3}$ was properly active and the performance was stable. Interestingly, neither of $\mathrm{SrFeO}_{3}-$ supported catalyst worked well in the co-feeding experiment. The selectivity dropped continuously because more $\mathrm{CO}_{2}$ and less $\mathrm{EO}$ was produced, presumably, as the support became depleted in oxygen. Worse performance was also observed in the direct epoxidation carried out in the cycling mode. Clearly, the presence of $\mathrm{O}_{2}$ in the feed resulted in more pronounced combustion of both $\mathrm{C}_{2} \mathrm{H}_{4}$ and the produced EO.

Table 1. Various modes of carrying out epoxidation of ethylene, comparison of selectivity and conversion. Each catalyst comprised support material impregnated with $15 \mathrm{wt} \%$ Ag.

\begin{tabular}{|c|c|c|c|}
\hline Support material & Experiment & Selectivity [\%] & Conversion[\%] \\
\hline \multirow[t]{6}{*}{$\mathrm{SrFeO}_{3}$} & Chemical looping & 37.6 & 2.05 \\
\hline & Direct epoxidation in a cycling mode & 24.0 & 8.6 \\
\hline & Direct epoxidation for: & & \\
\hline & $3 \mathrm{~min}$ & 18.8 & 10.0 \\
\hline & $30 \mathrm{~min}$ & 6.6 & 15.7 \\
\hline & $60 \mathrm{~min}$ & 5.4 & 20.2 \\
\hline \multirow[t]{6}{*}{$\left(\mathrm{CeO}_{2}\right) \mathrm{SSSrFeO}_{3}$} & Chemical looping & 62.3 & 7.3 \\
\hline & Direct epoxidation in a cycling mode & 54.5 & 7.2 \\
\hline & Direct epoxidation for: & & \\
\hline & $3 \min$ & 45.5 & 8.8 \\
\hline & $30 \mathrm{~min}$ & 12.3 & 9.5 \\
\hline & $60 \mathrm{~min}$ & 8.6 & 10.6 \\
\hline \multirow[t]{5}{*}{$\alpha-\mathrm{Al}_{2} \mathrm{O}_{3}$} & Chemical looping & 30.0 & 0.3 \\
\hline & Direct epoxidation in a cycling mode & 36.1 & 4.7 \\
\hline & Direct epoxidation for: & & \\
\hline & $3 \mathrm{~min}$ & 33.2 & 4.6 \\
\hline & $30 \mathrm{~min}$ & 30.1 & 4.3 \\
\hline
\end{tabular}


Methodology:

Chemical looping experiment: Three cycles - results listed in the table are from the third cycle. One cycle comprised: i) 2 min purge with $\mathrm{N}_{2}$, ii) 1.5 min reduction in 2.58 vol\% $\mathrm{C}_{2} \mathrm{H}_{4}$ (in $\mathrm{N}_{2}$ ), iii) 2 min purge with $\mathrm{N}_{2}$, iv) 15 min reoxidation in 10.5 vol\% $\mathrm{O}_{2}$ (in $\mathrm{N}_{2}$ ).

Direct epoxidation in a cycling mode: Three cycles - results listed in the table are from the third cycle. One cycle consisted of: i) 2 min purge with $\mathrm{N}_{2}$, ii) 1.5 min epoxidation in a mixture of $2.58 \mathrm{vol} \% \mathrm{C}_{2} \mathrm{H}_{4}, 5 \mathrm{vol} \% \mathrm{O}_{2}$ (in $\mathrm{N}_{2}$ ), iii) 2 min purge with $\mathrm{N}_{2}$, iv) 15 min reoxidation in $5 \mathrm{vol} \% \mathrm{O}_{2}\left(\right.$ in $\left.\mathrm{N}_{2}\right)$.

Direct epoxidation carried out for up to 1 hour in a mixture of 2.58 vol\% $\mathrm{C}_{2} \mathrm{H}_{4}, 5 \mathrm{vol} \% \mathrm{O}_{2}$ (in $\mathrm{N}_{2}$ ).

\section{Discussion}

Work by Chan et al. (2018) showed the feasibility of chemical looping epoxidation of ethylene, using $15 \mathrm{wt} \% \mathrm{Ag}$ on $\mathrm{SrFeO}_{3}$. In that study, the catalyst quickly deactivated, which was attributed to the oxidation step being slow and thus causing a loss of oxygen capacity when the sample was oxidised for a time shorter than that needed for complete oxidation. Here, we have shown that the addition of $\mathrm{CeO}_{2}$ to $\mathrm{SrFeO}_{3}$, either to the bulk or on the surface (via impregnation), improves the performance of the catalyst, both in terms of selectivity and conversion. Moreover, the CL-epoxidation of material with $\mathrm{CeO}_{2}$ incorporated in the bulk gave a stable production of ethylene oxide, with a selectivity of $60 \%$ at $10 \%$ conversion of $\mathrm{C}_{2} \mathrm{H}_{4}$, maintained over 15 redox cycles. This is already higher than $40-50 \%$ selectivity achievable for classical epoxidation with $\mathrm{O}_{2(\mathrm{~g})}$ on clean $\mathrm{Ag}$ surfaces without promoters $[2,11]$. Concerning the conversion, the $10 \%$ obtained here is also comparable, because, industrially, the conversion of $\mathrm{C}_{2} \mathrm{H}_{4}$ is kept $<10-15 \%$ to maintain control over the exothermic reactions (both epoxidation and combustion) and heat release [3].

Importantly, here we have shown that the repeatability of the experiment is good, most notably for $\left(\mathrm{CeO}_{2}\right) \mathrm{ss}\left(\mathrm{SrFeO}_{3}\right)$. Noteworthy, the method of impregnation, performed on $\left(\mathrm{CeO}_{2}\right) \mathrm{ss}\left(\mathrm{SrFeO}_{3}\right)$ for depositing of $\mathrm{Ag}$, did not influence the performance of this material in epoxidation, as the selectivity was essentially the same in all three batches. In contrast, a more significant variation in performance was observed among $\mathrm{CeO}_{2}$-impregnated samples. This material, $\left(\mathrm{CeO}_{2}\right) \mathrm{impr}\left(\mathrm{SrFeO}_{3}\right)$, required double impregnation (firstly $\mathrm{CeO}_{2}$, then $\mathrm{Ag}$ ), which might have introduced more variability to the final surface, highlighting the importance of the distribution of $\mathrm{CeO}_{2}$ and $\mathrm{Ag}$ and their interfaces with $\mathrm{SrFeO}_{3}$.

Results for epoxidation with $\mathrm{Ag}-\mathrm{CeO}_{2}$ showed that the properties of the oxygen storage material influence the products of CL-epoxidation. $\mathrm{CeO}_{2}$ did not catalyse epoxidation nor was it an optimal oxygen reservoir for $\mathrm{C}_{2} \mathrm{H}_{4}$ epoxidation on $\mathrm{Ag}$. The complete combustion achieved with $\mathrm{CeO}_{2}$ and the lack of the epoxide product (except for the first cycle) suggest three possibilities: i) $\mathrm{CeO}_{2}$ cannot provide oxygen to $\mathrm{Ag}$ directly and combustion happens on a bare $\mathrm{CeO}_{2}$ surface, ii) $\mathrm{CeO}_{2}$ provides oxygen to $\mathrm{Ag}$ too fast and gives total combustion, or iii) epoxide combusts before leaving the reactor. As the presence of the epoxide was detected in the first cycle, the last possibility can be eliminated. From the phase diagram of $\mathrm{CeO}_{2}$ [18] and the TPR of $\mathrm{CeO}_{2}$ in $\mathrm{C}_{2} \mathrm{H}_{4}$ (given in SFig. 7 in the supporting information), 
the first option can be ruled out; $\mathrm{CeO}_{2}$ did not reduce at $T<400^{\circ} \mathrm{C}$ in $\mathrm{C}_{2} \mathrm{H}_{4}$. This leaves the second possibility, viz. oxygen diffuses from the solid oxygen reservoir to the catalyst directly as suggested by Chan et al. [6], noting that $\mathrm{CeO}_{2}$ does not release $\mathrm{O}_{2(\mathrm{~g})}$ at $270^{\circ} \mathrm{C}$. As $\mathrm{CO}_{2}$ was the only product of epoxidation on $\mathrm{Ag}-\mathrm{CeO}_{2}$, the transport of oxygen from ceria to $\mathrm{Ag}$ must have favoured the creation of nucleophilic O-species, which are known to promote total combustion of $\mathrm{C}_{2} \mathrm{H}_{4}$ on silver $[11,19]$. Interestingly, previous studies on the direct epoxidation with $\mathrm{Ag}-\mathrm{CeO}_{2}$ have shown that, in the presence of $\mathrm{O}_{2(\mathrm{~g})}$, ethylene also combusts to $\mathrm{CO}_{2}[20]$, indicating that the absorption of $\mathrm{O}_{2(\mathrm{~g})}$ on to ceria and then its mobility between $\mathrm{CeO}_{2}$ and $\mathrm{Ag}$ might be faster than adsorption and dissolution of $\mathrm{O}_{2(\mathrm{~g})}$ directly on an Ag-surface.

As discussed by Chan et al. [6], the chemical looping route for epoxidation requires an intimate contact between oxygen carrier and silver. In experiments where both $\mathrm{Ag}$ and $\mathrm{SrFeO}_{3}$ were present but not in intimate contact (viz. mixed particles of $\mathrm{Ag}-\mathrm{Al}_{2} \mathrm{O}_{3}$ and $\mathrm{SrFeO}_{3}$ ), the only product of reduction was $\mathrm{CO}_{2}$. Here, the experiment with $\mathrm{Ag}-\mathrm{CeO}_{2}$ resulted in the total combustion of ethylene, while bare $\mathrm{CeO}_{2}$ did not react with $\mathrm{C}_{2} \mathrm{H}_{4}$ at all. This indicates that the intimate contact between $\mathrm{Ag}$ and $\mathrm{CeO}_{2}$ is not beneficial in epoxidation, in contrast to the intimate contact between $\mathrm{Ag}$ and $\mathrm{SrFeO}_{3}$. The fact that the character of the material supporting $\mathrm{Ag}$ influences the distribution of the products of epoxidation has also been observed in direct epoxidation with $\mathrm{O}_{2(\mathrm{~g})}$, e.g., by Chongterdtoonskul et al. [21].

Finally, the results from $\mathrm{Ag}-\mathrm{CeO}_{2}$ shed some light on the differences in performance of $\left(\mathrm{CeO}_{2}\right)$ impr $\left(\mathrm{SrFeO}_{3}\right)$. As Ag- $\left(\mathrm{CeO}_{2}\right) \operatorname{impr}\left(\mathrm{SrFeO}_{3}\right)$ was the double-impregnated sample, the $\mathrm{Ag}$ was also distributed directly on the $\mathrm{CeO}_{2}$ nanoparticles (as shown in SFig. 2 in the supporting information). If the contact with $\mathrm{CeO}_{2}$ was better than with $\mathrm{SrFeO}_{3}$, then the material might have favoured total combustion (as in $\mathrm{Ag}-\mathrm{CeO}_{2}$ ), resulting in poor selectivity.As the rate of epoxidation of $\mathrm{C}_{2} \mathrm{H}_{4}$ on a conventional catalyst strongly depends on $p \mathrm{O}_{2}$ [2], it is reasonable to assume that a good supporting material for chemical looping epoxidation should have a high chemical potential of oxygen, $\mu_{\mathrm{O} 2}$. The previous study by Chan et al. (2018) used $\mathrm{SrFeO}_{3}$, which can release appreciable $\mathrm{O}_{2(\mathrm{~g})}$ at $\sim 400^{\circ} \mathrm{C}$ in air $[7,10]$. The modification proposed in this work, namely the introduction of a small amount of $\mathrm{CeO}_{2}$, resulted in increasing the effective $\mu_{\mathrm{O} 2}$ and improving the kinetics of redox reactions, as seen in TPR in $\mathrm{H}_{2}$ (results in Fig. 3) and epoxidation in $\mathrm{C}_{2} \mathrm{H}_{4}$ (results in Fig. 4). The trend in the observed rate of oxygen release was: $\left(\mathrm{CeO}_{2}\right) \mathrm{ss}\left(\mathrm{SrFeO}_{3}\right)>\left(\mathrm{CeO}_{2}\right) \mathrm{impr}\left(\mathrm{SrFeO}_{3}\right)>\mathrm{SrFeO}_{3}$. For the $\mathrm{CeO}_{2}$-containing materials, the faster reduction indicates either doping of $\mathrm{Ce}$ to the perovskite or phase cooperation. The presence of $\mathrm{Ce}^{4+/ 3+}$ in the perovskite structure would have resulted in a decreased number of vacancies and higher oxygen content $[12,22]$. On the other hand, had the $\mathrm{CeO}_{2}$ stayed as a separate phase, but in intimate contact with other oxides, it might have also influenced the properties of the perovskite by phase cooperation [18], as described below. Here, the XRD results indicated that doping was possible only to a small degree and $\mathrm{CeO}_{2}$ stayed mostly as a separate phase. Therefore, the cooperation between phases was, most likely, the dominant reason for the change in properties. 
Cooperation between two phases has been previously observed for $\mathrm{CeO}_{2}$ and $\mathrm{Fe}_{2} \mathrm{O}_{3}$ [23], resulting in enhanced reducibility of $\mathrm{Fe}_{2} \mathrm{O}_{3}$ at lower temperatures and at an increased rate than for either pure $\mathrm{Fe}_{2} \mathrm{O}_{3}$ or pure $\mathrm{CeO}_{2}$ alone. In the work of Luo et al. [24], the synergistic effect between the oxides was ascribed to the inhomogeneity of the material and abundance of $\mathrm{CeO}_{2}-\mathrm{Fe}_{2} \mathrm{O}_{3}$ interfaces. A possible mechanism presented by Machida et al. [18] proposed that $\mathrm{CeO}_{2}$ could act as an oxygen gateway. In reduction, $\mathrm{CeO}_{2}$ by itself would quickly lose the mobile surface oxygen, $\mathrm{O}_{\mathrm{s}}$, and would become mainly inactive $\left(\mathrm{CeO}_{2-x}\right)$. However, if $\mathrm{CeO}_{2}$ were in contact with $\mathrm{Fe}_{2} \mathrm{O}_{3}$, then iron oxide would act as an oxygen reservoir, donating bulk oxygen, $\mathrm{O}_{\mathrm{b}}$, to $\mathrm{CeO}_{2-x}$, and thus allowing the reduction to be continued. The phase cooperation would also be noticeable during oxidation, as $\mathrm{CeO}_{2}$ would allow for quick incorporation of $\mathrm{O}_{2(\mathrm{~g})}$ into $\mathrm{O}_{\mathrm{s}}$, to be later transported and stored in the $\mathrm{Fe}_{2} \mathrm{O}_{3}$ structure as $\mathrm{O}_{\mathrm{b}}$. The proposed mechanism requires fast O-transport, which would have been assured by very mobile oxygen vacancies in $\mathrm{CeO}_{2}$. Similar phase cooperation has been observed between $\mathrm{CeO}_{2}$ and: $\mathrm{CuMnO}_{2}$ [25], $\mathrm{Mn}_{2} \mathrm{O}_{3}, \mathrm{Mn}_{\mathrm{x}} \mathrm{Fe}_{1-\mathrm{x}} \mathrm{O}_{\mathrm{y}}$ (both in [26]); $\mathrm{CuO}[27,28], \mathrm{La}_{2} \mathrm{O}_{2} \mathrm{SO}_{4}$ [29] and tungstophosphoric acid HPW [30]. Acting as a gateway, $\mathrm{CeO}_{2}$ would provide an interface that quickly dissociates $\mathrm{O}_{2(\mathrm{~g})}$ and converts it to $\mathrm{O}_{\mathrm{s}}$ (or during reduction, transfers $\mathrm{O}_{\mathrm{s}}$ to the gas phase species). Therefore, the gateway mechanism implies that $\mathrm{CeO}_{2}$ should be exposed to the gas phase and both $\mathrm{CeO}_{2}$-metal oxide and $\mathrm{CeO}_{2}$-gas interfaces would be important. Here, the nanoparticles of $\mathrm{CeO}_{2}$ created on the $\mathrm{CeO}_{2}$-impregnated $\mathrm{SrFeO}_{3}$ should have resulted in the largest number of gateways for oxygen. However, the rate of reduction of the $\mathrm{CeO}_{2}$-impregnated sample was lower than the rate observed for the sample with $\mathrm{CeO}_{2}$ added by ball milling, as seen both in the TGA (Fig. 3 and 4) and in the packed bed experiments (Fig. 6). Therefore, the phase cooperation was more pronounced when $\mathrm{CeO}_{2}$ was dispersed in bulk, not on the surface. A possible explanation is offered by the observation by Luo et al. [24] that bulk inhomogeneity in a two-phase material benefits the synergistic effect. The extent of phase cooperation would then depend on the extent and nature of the material- $\mathrm{CeO}_{2}$ interface. Here, we propose that for $\left(\mathrm{CeO}_{2}\right) \mathrm{ss}\left(\mathrm{SrFeO}_{3}\right)$, which consists of grains of $\mathrm{CeO}_{2}$ mixed within $\mathrm{SrFeO}_{3}$, an additional role of $\mathrm{CeO}_{2}$ could be to act as a short-cut for oxygen transport. Grains of $\mathrm{CeO}_{2}$ in contact with $\mathrm{SrFeO}_{3}$ could help with ionic conduction of oxygen, providing oxygen that would otherwise be inaccessible on the time scale needed for the reaction. It is not possible to say from the experiments here which mechanism (i.e., gateway or short-circuit, or more likely both) is responsible for the improved performance of the $\left(\mathrm{CeO}_{2}\right) \mathrm{ss}\left(\mathrm{SrFeO}_{3}\right)$ and further work is needed to elucidate the exact role of $\mathrm{CeO}_{2}$.

Chan et al. [6] suggested that the deactivation with cycling for an $\mathrm{Ag}-\mathrm{SrFeO}_{3}$ catalyst was caused by the slow rate of reoxidation, meaning the catalyst was not fully regenerated before the next reduction cycle. It should be noted that Chan et al. [6] used a fixed time for reoxidation of the support of shorter duration than that needed for complete oxidation. In the present work, the performance of a similar material also decreased with cycling, both for selectivity towards EO and conversion of $\mathrm{C}_{2} \mathrm{H}_{4}$. Similar behaviour was also seen for $\left(\mathrm{CeO}_{2}\right) \mathrm{impr}\left(\mathrm{SrFeO}_{3}\right)$. As observed in the TGA (Fig. 4), the oxidation was 
indeed significantly slower than reduction. On the other hand, when samples were cycled in the TGA, the poor regeneration did not influence the overall ability of the oxygen storage material to supply oxygen, as the mass loss in reduction remained the same (as seen in SFig. 6 in the supporting information). A similar conclusion was drawn from the experiments in the packed bed where the total oxygen release stabilized after the first few redox cycles, as seen in Fig. 7. It should also be noted that the amount of oxygen removed during a cycle in the TGA was larger than that removed in the shorter reduction in the packed bed. Therefore, it may be that for $\mathrm{SrFeO}_{3}$ and $\left(\mathrm{CeO}_{2}\right) \mathrm{impr}\left(\mathrm{SrFeO}_{3}\right)$, the oxidation state of the surface gradually falls to a level where it cannot provide oxygen at a suitable potential for epoxidation (giving mainly combustion). The same does not seem to be true for $\left(\mathrm{CeO}_{2}\right) \mathrm{ss}\left(\mathrm{SrFeO}_{3}\right)$, which stabilised in a state that gave stable and highly selective production of EO. The above does not rule out that the regeneration period might be crucial in assuring stable performance. However, here, the amount of oxygen removed during each cycle was small, so even if the $\left(\mathrm{CeO}_{2}\right) \mathrm{ss}\left(\mathrm{SrFeO}_{3}\right)$ did not fully regenerate, if there was sufficiently fast oxygen transport from the oxygen-rich bulk, the oxygen-depleted surface would have regenerated. The best performance might then be expected from $\left(\mathrm{CeO}_{2}\right) \mathrm{ss}\left(\mathrm{SrFeO}_{3}\right)$, if $\mathrm{CeO}_{2}$ in the bulk did indeed improve ionic conductivity, effectively accelerating the delivery of $\mathrm{O}_{\mathrm{b}}$ from $\mathrm{SrFeO}_{3}$ to the surface. It may also be that the oxidation of $\left(\mathrm{CeO}_{2}\right) \mathrm{ss}\left(\mathrm{SrFeO}_{3}\right)$ was sufficiently fast to regenerate the surface (the TGA results indicate that oxidation is initially fast then falls off in rate); in this case, the $\mathrm{CeO}_{2}$ might also be assisting the oxidation via the gateway effect.

This study shows a possible improvement of CL-epoxidation, achieved by adding $\mathrm{CeO}_{2}$ to the main reservoir of oxygen, $\mathrm{SrFeO}_{3}$. Varying the amounts of $\mathrm{CeO}_{2}$ as a dopant was not investigated for CLepoxidation, and an optimal $\mathrm{CeO}_{2}$ content is yet to be determined. Moreover, further improvement of CL-epoxidation might include inhibitors and promoters, which are commonly used in the direct epoxidation of ethylene [3]. Also taking note of classical gas-phase epoxidation, a pre-treatment of catalyst might be beneficial, helping with activation of the catalyst, e.g., by removing any surface impurities (carbonates, hydroxides), and by influencing $\mathrm{Ag}$ distribution or improving phase cooperation. The impact of each of the factors might be difficult to separate as all above require temperature treatment (e.g., surface purification at min. $550^{\circ} \mathrm{C}$ ) and will happen simultaneously during the heat up. Also, detail understanding of the mechanism in the chemical looping reaction is at this stage missing. More insight might come from dedicated DFT calculations or in-situ experiments using surface-sensitive techniques (e.g., XPS).

\section{Conclusions}

This work demonstrates that epoxidation via chemical looping route can result in good selectivity for ethylene oxide at a reasonable conversion range. The results are close to the values obtained in the classical epoxidation where $\mathrm{O}_{2}$ is provided in the gas phase. The outcome of the CL-epoxidation depends strongly on the solid support that provides oxygen directly to the $\mathrm{Ag}$ catalyst. Higher 
conversion and selectivity were obtained when the oxygen reservoir, $\mathrm{SrFeO}_{3}$, was enriched with $5 \mathrm{~mol} \%$ $\mathrm{CeO}_{2}$, either on the surface or in bulk. The presence of $\mathrm{CeO}_{2}$ increased the effective $p \mathrm{O}_{2}$ of the supports, improving the rate of reduction and reoxidation during CL-epoxidation. The best and very stable performance, at $60 \%$ selectivity and $10 \% \mathrm{C}_{2} \mathrm{H}_{4}$ conversion, was obtained for the catalyst containing $\mathrm{CeO}_{2}$ in bulk.

\section{Acknowledgements}

The research was carried out with the financial support from EPSRC Impact Acceleration Account Part 3.

\section{References}

[1] C.H. McAteer, R. Murugan, Y.V. Subba Rao, Heterogeneously Catalyzed Synthesis of Heterocyclic Compounds (Chapter 6), in: E.F.V. Scriven, C.A. Ramsden (Eds.), Adv. Heterocycl. Chem., Academic Press, 2017, pp. 173-205.

[2] R.A. van Santen, C.P.M. de Groot, The mechanism of ethylene epoxidation, J. Catal. 98 (1986) 530-539. doi:10.1016/0021-9517(86)90341-6.

[3] S. Rebsdat, D. Mayer, Ethylene Oxide, in: Ullmanns Encycl. Ind. Chem., American Cancer Society, 2001.

[4] K. Weissermel, H.-J. Arpe, Industrial Organic Chemistry, John Wiley \& Sons, 2008.

[5] N. Macleod, J.M. Keel, R.M. Lambert, The Effects of Catalyst Aging Under Industrial Conditions: Ethylene Oxide Conversion over Ag-Cs $/ \alpha-\mathrm{Al}_{2} \mathrm{O}_{3}$ Catalysts, Catal. Lett. 86 (2003) 51-56. doi:10.1023/A:1022602807322.

[6] M.S.C. Chan, E. Marek, S.A. Scott, J.S. Dennis, Chemical looping epoxidation, J. Catal. 359 (2018) 1-7. doi:10.1016/j.jcat.2017.12.030.

[7] E. Marek, W. Hu, M. Gaultois, C.P. Grey, S.A. Scott, The use of strontium ferrite in chemical looping systems, Appl. Energy. 223 (2018) 369-382. doi:10.1016/j.apenergy.2018.04.090.

[8] A. Coelho, TOPAS Academic, V5 Coelho Software, Coelho Software, Brisbane, Australia, 2013. http://www.topas-academic.net/ (accessed April 14, 2017).

[9] N.E. Trofimenko, H. Ullmann, J. Paulsen, R. Müller, Structure, oxygen stoichiometry and electrical conductivity in the system Sr-Ce-Fe-O, Solid State Ion. 99 (1997) 201-214. doi:10.1016/S0167-2738(97)00262-2.

[10] C.Y. Lau, M.T. Dunstan, W. Hu, C.P. Grey, S.A. Scott, Large scale in silico screening of materials for carbon capture through chemical looping, Energy Env. Sci. (2017). doi:10.1039/C6EE02763F.

[11] V.I. Bukhtiyarov, A. Knop-Gericke, Ethylene Epoxidation over Silver Catalysts (Chapter 9), in: Nanostructured Catal., 2011: pp. 214-247.

[12] F. Deganello, L.F. Liotta, A. Longo, M.P. Casaletto, M. Scopelliti, Cerium effect on the phase structure, phase stability and redox properties of Ce-doped strontium ferrates, J. Solid State Chem. 179 (2006) 3406-3419. doi:10.1016/j.jssc.2006.06.027.

[13] F. Solymosi, The bonding, structure and reactions of $\mathrm{CO}_{2}$ adsorbed on clean and promoted metal surfaces, J. Mol. Catal. 65 (1991) 337-358. doi:10.1016/0304-5102(91)85070-I.

[14] A. Trovarelli, Catalytic Properties of Ceria and $\mathrm{CeO}_{2}$-Containing Materials, Catal. Rev. 38 (1996) 439-520. doi:10.1080/01614949608006464.

[15] H. Falcón, J.A. Barbero, J.A. Alonso, M.J. Martínez-Lope, J.L.G. Fierro, $\mathrm{SrFeO}_{3-\delta}$ Perovskite Oxides: Chemical Features and Performance for Methane Combustion, Chem. Mater. 14 (2002) 2325-2333. doi:10.1021/cm0112921.

[16] C.B. Alcock, V.P. Itkin, M.K. Horrigan, Vapour Pressure Equations for the Metallic Elements: 298-2500 K, Can. Metall. Q. 23 (1984) 309-313. doi:10.1179/cmq.1984.23.3.309.

[17] M.A. Asoro, D. Kovar, P.J. Ferreira, In situ Transmission Electron Microscopy Observations of Sublimation in Silver Nanoparticles, ACS Nano. 7 (2013) 7844-7852. doi:10.1021/nn402771j. 
[18] M. Machida, T. Kawada, H. Fujii, S. Hinokuma, The Role of $\mathrm{CeO}_{2}$ as a Gateway for Oxygen Storage over $\mathrm{CeO}_{2}-\mathrm{Grafted} \mathrm{Fe}_{2} \mathrm{O}_{3}$ Composite Materials, J. Phys. Chem. C. 119 (2015) 24932 24941. doi:10.1021/acs.jpcc.5b09876.

[19] K.C. Waugh, M. Hague, Investigation of the Origins of Selectivity in Ethylene Epoxidation on Promoted and Unpromoted $\mathrm{Ag} / \alpha-\mathrm{Al}_{2} \mathrm{O}_{3}$ Catalysts: A Detailed Kinetic, Mechanistic and Adsorptive Study (Chapter 7), in: S.T. Oyama (Ed.), Mech. Homog. Heterog. Epoxidation Catal., Elsevier, Amsterdam, 2008: pp. 233-263.

[20] S. Rojluechai, S. Chavadej, J.W. Schwank, V. Meeyoo, Catalytic activity of ethylene oxidation over $\mathrm{Au}, \mathrm{Ag}$ and $\mathrm{Au}-\mathrm{Ag}$ catalysts: Support effect, Catal. Commun. 8 (2007) 57-64. doi:10.1016/j.catcom.2006.05.029.

[21] A. Chongterdtoonskul, J.W. Schwank, S. Chavadej, Effects of oxide supports on ethylene epoxidation activity over Ag-based catalysts, J. Mol. Catal. Chem. 358 (2012) 58-66. doi:10.1016/j.molcata.2012.02.011.

[22] N.E. Trofimenko, H. Ullmann, Oxygen stoichiometry and mixed ionic-electronic conductivity of $\mathrm{Sr}_{1-\mathrm{a}} \mathrm{Ce}_{\mathrm{a}} \mathrm{Fe}_{1-\mathrm{b}} \mathrm{Co}_{\mathrm{b}} \mathrm{O}_{3-\mathrm{x}}$ perovskite-type oxides, J. Eur. Ceram. Soc. 20 (2000) 1241-1250. doi:10.1016/S0955-2219(99)00292-7.

[23] K. Li, M. Haneda, Z. Gu, H. Wang, M. Ozawa, Modification of $\mathrm{CeO}_{2}$ on the redox property of $\mathrm{Fe}_{2} \mathrm{O}_{3}$, Mater. Lett. 93 (2013) 129-132. doi:10.1016/j.matlet.2012.09.039.

[24] Y. Luo, R. Chen, W. Peng, G. Tang, X. Gao, Inverse $\mathrm{CeO}_{2} \mathrm{Fe}_{2} \mathrm{O}_{3}$ catalyst for superior lowtemperature CO conversion efficiency, Appl. Surf. Sci. 416 (2017) 911-917. doi:10.1016/j.apsusc.2017.04.225.

[25] X. Huang, C. Ni, G. Zhao, J.T.S. Irvine, Oxygen storage capacity and thermal stability of the $\mathrm{CuMnO}_{2}-\mathrm{CeO}_{2}$ composite system, J. Mater. Chem. A. 3 (2015) 12958-12964. doi:10.1039/C5TA01361E.

[26] M. Machida, M. Ueno, T. Omura, S. Kurusu, S. Hinokuma, T. Nanba, O. Shinozaki, H. Furutani, $\mathrm{CeO}_{2}$-Grafted $\mathrm{Mn}-\mathrm{Fe}$ Oxide Composites as Alternative Oxygen-Storage Materials for Three-Way Catalysts: Laboratory and Chassis Dynamometer Tests, Ind. Eng. Chem. Res. 56 (2017) 3184-3193. doi:10.1021/acs.iecr.6b04468.

[27] A. Hornés, A.B. Hungría, P. Bera, A.L. Cámara, M. Fernández-García, A. Martínez-Arias, L. Barrio, M. Estrella, G. Zhou, J.J. Fonseca, J.C. Hanson, J.A. Rodriguez, Inverse $\mathrm{CeO}_{2} / \mathrm{CuO}$ Catalyst As an Alternative to Classical Direct Configurations for Preferential Oxidation of CO in Hydrogen-Rich Stream, (2009). doi:10.1021/ja9089846.

[28] S.T. Hossain, E. Azeeva, K. Zhang, E.T. Zell, D.T. Bernard, S. Balaz, R. Wang, A comparative study of $\mathrm{CO}$ oxidation over $\mathrm{Cu}-\mathrm{O}-\mathrm{Ce}$ solid solutions and $\mathrm{CuO} / \mathrm{CeO}_{2}$ nanorods catalysts, Appl. Surf. Sci. 455 (2018) 132-143. doi:10.1016/j.apsusc.2018.05.101.

[29] D. Zhang, T. Kawada, F. Yoshioka, M. Machida, Oxygen Gateway Effect of $\mathrm{CeO}_{2} / \mathrm{La}_{2} \mathrm{O}_{2} \mathrm{SO}_{4}$ Composite Oxygen Storage Materials, ACS Omega. 1 (2016) 789-798. doi:10.1021/acsomega.6b00262.

[30] Y. Geng, S. Xiong, B. Li, Y. Liao, X. Xiao, S. Yang, $\mathrm{H}_{3} \mathrm{PW}_{12} \mathrm{O}_{40}$ Grafted on $\mathrm{CeO}_{2}$ : A HighPerformance Catalyst for the Selective Catalytic Reduction of $\mathrm{NO}_{\mathrm{x}}$ with $\mathrm{NH}_{3}$, Ind. Eng. Chem. Res. 57 (2018) 856-866. doi:10.1021/acs.iecr.7b03947. 